\section{A instituição psiquiátrica moderna sob a perspectiva organizacional}

\section{The modern psychiatric institution from an organizational perspective}

\section{Fábio Vizeu}

Centro Universitário Positivo (Unicenp) Rua Prof. Pedro Viriato Parigot de Souza, 5300

Campo Comprido 81280-330 Curitiba - Paraná

vizeu@unicenp.br
VIZEU, F.: A instituição psiquiátrica moderna sob a perspectiva organizacional. História, Ciências, Saúde - Manguinhos, v. 12, n. 1, p. 33-49, jan.-abr. 2005.

Este ensaio analisa o desenvolvimento da instituição psiquiátrica moderna, representado de maneira mais significativa pelo surgimento da organização manicomial tradicional. Nesse tipo de instituição, o processo de controle comportamental opera nas mesmas bases epistemológicas que deram ensejo ao modelo burocrático de dominação, ou seja, de acordo com a orientação racional instrumental que legitima a previsibilidade e a eficiência como princípios centrais. Em contrapartida, observa-se recentemente uma ruptura com tal tipo organizacional, expressa pelos movimentos antimanicomial e da antipsiquiatria, que se deram, primeiro, sob a forma de denúncia e crítica ao telos contraditório patente no instituto manicomial, e depois a partir de propostas reformistas. Em último plano, tal mudança de paradigma ocorre no sentido de uma humanização da interação entre os diferentes atores do modelo manicomial.

PALAVRAS-CHAVE: instituição psiquiátrica moderna, modelo manicomial, reforma psiquiátrica, lógica organizacional.

VIZEU, F.: The modern psychiatric institution from an organizational perspective. História, Ciências, Saúde - Manguinhos, v. 12, n. 1, p. 33-49, Jan.-Apr. 2005.

The essay analyzes the development of the modern psychiatric institution, represented most importantly by the emergence of the traditional asylum organization. In this type of institution, the process of behavioral control operates upon the same epistemological bases that fostered the bureaucratic model of domination - in other words, in consonance with the instrumentalrational approach that legitimizes as key principles predictability and efficacy. In contrast, there has recently been a break with this organizational type, expressed through the antiasylum and anti-psychiatry movements, chiefly in the form of denunciations and criticisms of the contradictory 'telos' so evident at asylums and, secondarily, in the form of reformist proposals. Lastly, this change in paradigm has moved towards humanizing interactions between actors within the asylum model.

KEYWORDS: modern psychiatric institution, asylum model, psychiatric reform, organizational logic. 
${ }^{1}$ Em certo sentido, o utilitarismo econômico pode ser considerado um valor da modernidade, $\mathrm{o}$ que, a princípio, configuraria uma 'nova moral'. Todavia seguimos a distinção feita por Weber (1991) entre a racionalidade instrumental e a racionalidade substantiva, em que a segunda é fundamentada em uma 'moral', e a primeira, fundamentada apenas no cálculo utilitário de conseqüências, quase sempre, levado a efeito sem considerações éticas e morais (Habermas, 1987).

\section{Introdução}

1 análise de como o mecanismo organizacional de burocratide valorização da disciplina, do controle e da verdade científica valores que podem ser sintetizados como a ligação entre a racionalidade instrumental e a filosofia utilitarista do capitalismo - pode ser muito bem verificada com o advento do modelo manicomial como forma de tratamento psiquiátrico legítimo e funcional para a organização social pretendida na era moderna. Tal modelo organizacional - o manicômio, o hospício - representa bem o impacto que tiveram a técnica e o modelo de ciências naturais no âmbito ético-moral da sociedade. A questão da loucura, antes vista como abarcando fortes componentes éticos e morais, com o advento do cientificismo passa a ser considerada primeiramente a partir do utilitarismo econômico. ${ }^{1}$

O manicômio como tipo organizacional pode ser caracterizado por dois elementos estruturais básicos: o internamento e isolamento como procedimento de tratamento da loucura (alienismo) e o uso severo de um mecanismo burocrático de controle para a manutenção da ordem no âmbito interno da organização. A partir de tais condições estruturais, é possível considerar o modelo manicomial como um caso extremo de condicionamento racionalinstrumental. Dado seu caráter radical de controle e subjugação do sujeito, não deixa espaço para a superação dos problemas de alienação que derivam do processo organizacional de burocratização. Assim, no modelo manicomial, a contradição subjacente ao sistema burocrático de organização vê-se escancarada na forma ambígua em que se estabelece o telos desse tipo: o manicômio foi feito para curar a doença mental e para excluir e controlar o insano.

A partir dessa ambigüidade, muitos esforços acadêmicos têm buscado verificar a perversidade com que esse tipo organizacional trata o ser humano. Considerando que, sob a perspectiva administrativa, o manicômio - como instituição total - empreende a burocratização do comportamento (Goffman, 1996), tais esforços encaminham-se no mesmo sentido que a crítica ao modelo burocrático tratada pela sociologia das organizações (Burrell et al., 1979). Ou seja, a denúncia de um modelo epistemológico utilitarista e economicista, muitas vezes degradante da condição humana.

A denúncia do manicômio é feita por um movimento denominado 'antimanicomial', e a resposta e a busca de soluções giram em torno de um novo modelo institucional de tratamento e organização almejado pela 'reforma psiquiátrica'. Assim, o entendimento da questão da doença mental suscitado por tais movimentos é rico para elucidar um possível caminho a ser traçado para tais institui- 
ções, não somente no que tange à solução do problema da doença mental, mas também por configurar mudanças epistemológicas importantes para a condição humana pós-moderna.

Dois autores se destacam no sentido de revelar a ambigüidade presente no modelo manicomial: Michel Foucault (1992; 1997), em seu estudo sobre o surgimento do hospício e da psiquiatria moderna (Foucault), e Erwin Goffman (1996), ao apresentar o seu modelo ideal de organizações totais (Goffman, 1996). Seguimos com a apresentação das idéias destes dois autores, para, em seguida, tratar das questões do movimento antimanicomial e da reforma psiquiátrica. A partir da avaliação do movimento dialético do estabelecimento e da crise da instituição psiquiátrica moderna, procuramos evidenciar em que medida o modelo manicomial está sendo modificado, no sentido de permitir uma relação bilateral entre o corpo de profissionais da saúde mental e os pacientes. Por fim, a análise é empreendida no sentido de ressaltar os aspectos epistemológicos de tal desenvolvimento histórico da instituição psiquiátrica.

\section{Manicômio, psiquiatria moderna e organização total}

O surgimento do manicômio como forma de organização extremamente disciplinadora e coercitiva pode ser explicitado primeiramente por Foucault (1997), em seu texto sobre a História da loucura. Com um denso trabalho de reconstituição da psiquiatria clássica, o autor configura sua tese de que, na concepção da sociedade moderna, a loucura representava um mal a ser expurgado do meio social, já que era a contraposição ao bem mais precioso do homem moderno - a razão. Deste pensamento surge a noção de que, a despeito de qualquer interesse de reparação do mal subjacente ao tratamento médico, as instituições de tratamento psiquiátrico criadas na era moderna tinham por função principal o isolamento e a exclusão do doente mental do seio da sociedade. Daí ter sido essa forma de tratamento fundamentada basicamente na prática do internamento (também conhecida como alienismo - Cunha, 1986): os doentes mentais eram aglomerados em um mesmo espaço comum, isolados da sociedade da mesma maneira que outros casos históricos de marginalização social, como, por exemplo, o das colônias de leprosos.

De acordo com Foucault, tal interesse pela exclusão dos doentes mentais se dava ainda pelo telos de ordenação que se instituiu na sociedade moderna. Em função de tal interesse pela ordem social, recorria-se mesmo a questões de ordem econômica, política e moral para justificar a prática do internamento, como indica o autor, ao focalizar o pensamento moderno por trás da desumana prática da exclusão dos loucos: 
Qual era, portanto, a realidade visada através de toda essa população que, quase de um dia para o outro, viu-se reclusa e banida de modo mais severo que os leprosos? (...) Mas aquilo que para nós parece apenas uma sensibilidade indiferenciada, seguramente era, no homem clássico, uma percepção claramente articulada. É esse modo de percepção que cabe interrogar a fim de saber qual foi a forma de sensibilidade à loucura de uma época que se costuma definir através dos privilégios da Razão (Foucault, 1997, p. 55-6).

Dessa forma, Foucault reconstitui os pressupostos epistemológicos que fundamentam a psiquiatria, assim como o modelo organizacional destinado ao tratamento psiquiátrico na era moderna - o hospício. Essa instituição, antes de ser um local de cura, era um instrumento de que a sociedade se valia para a manutenção da ordem social, especialmente por meio do controle e da disciplina dos males que representavam uma ameaça aos valores da sociedade capitalista nascente. Assim, o emblema positivista da 'ordem e progresso' - que se estabelecia no século XIX como uma justificativa política para a coerção social - também se refletia na questão da loucura, alterando o próprio entendimento que dela se tinha (Foucault, 1992). Nesse sentido, Cunha (1986, p. 21) também considera que "o domínio do alienismo sobre a loucura redefinida foi, em pouco tempo, um elemento generalizado e incorporado às formas permanentes de gestão da sociedade burguesa".

É assim que o internamento nos manicômios não se restringia apenas aos doentes mentais, mas também a todo tipo de categoria desvirtuada da ordem social, como as prostitutas, os libertinos, os homossexuais, os viciados, os vagabundos, enfim, a todas as formas de inválidos que não se integravam à máquina produtiva do bem econômico. O internamento combatia então a ociosidade, o pior mal que poderia existir na sociedade que elevara o trabalho como vocação e virtude (Foucault, 1997).

A psiquiatria surgia então como uma forma legítima de conhecimento para a época, justificada como saber científico no momento em que "a insanidade conquistou suas dimensões de objeto" (Foucault, 1997, p. 105). Desta forma, o tratamento conduzido por essa disciplina tinha o status de saber especializado, e por isso mesmo não questionado. A ambigüidade da psiquiatria residia no fato de ela ser uma forma de poder altamente coercitiva e por vezes arbitrária, e contudo legítima para a sociedade centrada na racionalidade instrumental, que a via como um importante recurso para o controle e manutenção do status quo. Cunha, ao indicar o desdobramento do sentido dado à loucura com o advento do utilitarismo da sociedade moderna, assim considera o poder da psiquiatria: 
A ampliação do conceito da loucura (...) torna a psiquiatria um dispositivo mais eficaz e refinado: de "furiosa", a loucura tornase insidiosa, gruda-se à própria pele do indivíduo; torna-se, ademais, invisível - exceto para o olhar do especialista, que vê reforçada sua competência - e uma ameaça infinitamente maior a ser enfrentada, corporificada nas figuras ameaçadoras dos vadios, dos jogadores, das prostitutas e seus cafetões, dos ladrões, dos assassinos, de todos os tipos de "desordeiros" contidos na população urbana (Cunha, 1986, p. 25).

A função disciplinadora dos manicômios reflete assim o uso estratégico desse tipo organizacional para o controle social. Vários estudos sobre essas instituições corroboram a idéia. No Brasil, Machado et al. (1978) consideram que o interesse pela estatização das instituições psiquiátricas devia-se ao fato de estas organizações serem vistas como um importante mecanismo de controle da população revoltada e indisciplinada. Ou seja, era "uma estratégia de normalização que deve fornecer um corpo concreto (...) a ação do Estado" que "permite a aplicação de técnicas médico-políticas de controle em proveito de um Estado cuja ação legal é medicamente orientada" (p. 492). Esse enfoque da instituição manicomial, produzido exclusivamente em razão de uma preocupação com a ordem pública, também está presente no estudo de Cunha (1986) sobre o Juquery, um importante manicômio que atendia a população da cidade de São Paulo: o grande número de internos do Juquery, de não-insanos, se explicava pelo interesse em 'sanar' a crescente metrópole de seus males sociais, tais como a prostituição, o alcoolismo e até mesmo o desemprego.

Assim, a instituição manicomial se configurou não apenas como o locus onde se estabelecia a técnica do conhecimento psiquiátrico, já que essa organização representava a própria técnica psiquiátrica aplicada. Isso porque, com a especialização do conhecimento médico, o manicômio eleva-se ao grau de instituição hospitalar. A despeito dos benefícios que tal desdobramento possa trazer, ele apenas serviu para intensificar as arbitrariedades presentes no modelo manicomial, considerando a origem da organização médico-hospitalar nas instituições militares e a subseqüente influência da disciplina militar sobre a lógica operacional da organização hospitalar (Foucault, 1992, p. 99-111). E assim que os mecanismos de coordenação da vida humana nos hospitais - tais como a análise do espaço, a gestão do desenvolvimento da ação, a vigilância permanente e o registro contínuo - seguem o mesmo critério da estrutura militar, ou seja, a severa formalização do comportamento, representada pelo sistema burocrático de controle.

A partir desse último aspecto o modelo organizacional revelado por Goffman (1996) é muito elucidativo para o entendimento dos efeitos da dimensão burocrática sobre a vida dentro dos hospitais 
psiquiátricos. Por meio da análise de organizações caracterizadas pelo internamento e severo controle burocrático - tais como manicômios, prisões e conventos -, o autor criou o conceito de "instituição total", considerada por ele como um modelo ideal-típico capaz de verificar a rotina em tais organizações, assim como seus aspectos degradantes para a personalidade do indivíduo. Segundo Goffman (1996, p. 11): "Uma instituição total pode ser definida como um local de residência e trabalho onde um grande número de indivíduos com situação semelhante, separados da sociedade mais ampla por considerado espaço de tempo, levam uma vida fechada e formalmente administrada".

Goffman define o caráter totalizante dessas instituições pela condição de internamento dada a seu público, como indica o seguinte trecho: "seu 'fechamento' ou seu caráter total é simbolizado pela barreira à relação social com o mundo externo e por proibições a saídas que muitas vezes estão incluídas no esquema físico" (1996, p. 16). Todavia, existem autores que consideram o aspecto total desse modelo organizacional como advindo da rigorosa disciplina organizacional imposta aos internos, tendo em vista que "muitas das características que Goffman imagina estarem em função da totalidade do sistema estejam ou existam mais em função da estrutura interna do sistema" (Argyris, 1975, p. 314). Ou seja, na estrutura caracterizada pelas prerrogativas burocráticas, tais como a severa delimitação entre a autoridade formal e a subordinação, o rigor no cumprimento das regras e normas racionais e a impessoalidade com que se devem cumprir as interações entre as pessoas. De fato, Goffman (1996, p. 18) considera a importância da disciplina burocrática na constituição funcional das instituições totais: "O controle de muitas necessidades humanas pela organização burocrática de grupos completos de pessoas - seja ou não uma necessidade ou meio eficiente de organização social nas circunstâncias - é o fato básico das instituições totais".

A orientação para a eficiência (racionalidade instrumental) subjacente ao modelo burocrático de coordenação e controle pode ser expressa pelo fato de a disciplina ser um princípio fundamental em tal sistema administrativo. A legitimidade da ordem e do controle impingidos pela disciplina burocrática sustenta-se exclusivamente no caráter racional-instrumental da burocracia (Weber, 1974).

De acordo com Foucault (1987, p. 153), a disciplina se configura como "um poder que, em vez de se apropriar e de retirar, tem como função maior adestrar". O autor define três esferas básicas nas quais a disciplina se processa: o espaço, o tempo e os movimentos, entendendo que o minucioso detalhamento e a exaustiva codificação dessas dimensões "permitem o controle minucioso das operações do corpo, que realizam a sujeição constante de suas forças e lhes impõem uma relação de docilidade-utilidade" (id. ibid., p. 126). 
Foucault ainda assevera que: “Se a exploração econômica separa a força e o produto do trabalho, digamos que a coerção disciplinar estabelece no corpo o elo coercitivo entre uma aptidão aumentada e uma dominação acentuada" (id. ibid, p. 127).

Além da minuciosa regulamentação de todas as atividades relacionadas ao espaço na organização, ao tempo de execução das atividades e às ações empreendidas pelos internos, a disciplina nas organizações totais é efetuada a partir de um sistema formalizado de vigilância. De acordo com Goffman (1996, p. 18), a função da vigilância nas instituições totais é "fazer com que todos façam o que foi claramente indicado como exigido, sob condições de que a infração de uma pessoa tende a salientar-se diante da obediência visível e constantemente examinada dos outros". Além da vigilância, são considerados como importantes mecanismos disciplinadores a punição/recompensa e o exame (Foucault, 1987), sendo este último verificado sob a forma de registro documental e escrito.

A doutrinação imposta pela disciplina formal das instituições totais revela um direcionamento especificamente estratégico dado a essas ações. $\mathrm{O}$ interesse exclusivo em aplicar a disciplina consiste no controle da ordem da instituição, vista como um sistema independente equilibrado. Isso pode ser observado pela tensão que envolve a dimensão doméstica e o mundo institucional dessas organizações, como sugere Goffman (1996, p. 23-4): "as instituições totais realmente não procuram uma vitória cultural. Criam e mantêm um tipo específico de tensão entre o mundo doméstico e o mundo institucional, e usam esta tensão persistente como uma força estratégica no controle de homens".

O principal problema relacionado à disciplina empregada nas instituições totais é denominado por Goffman como a "mortificação do eu". Corresponde à contínua mutilação da identidade do indivíduo quando este se depara com a homogeneização subjacente aos mecanismos disciplinares, seja pelo fato de o sistema institucional submeter o interno a diversos procedimentos que deterioram a identificação do sujeito com seus antigos papéis sociais; seja pela transformação do interno em objeto - dada especialmente pela perda das posses relativas à identidade, como o nome e as roupas. Ambas se processam em razão do princípio da impessoalidade, premissa da lógica de burocratização. De fato, considerando que "a divisão equipe dirigente/internado é uma conseqüência básica da direção burocrática de grande número de pessoas" (id. ibid., p. 20), os mecanismos disciplinares das instituições totais também são constituídos de maneira a intensificar a diferenciação.

Um estudo feito sobre o sistema manicomial de Santa Catarina, Brasil, atesta bem tal aspecto funcional da diferenciação entre internos e supervisores. Teixeira (1993) demonstra que, na institui- 
ção por ele estudada, existia uma certa proximidade entre os atendentes - supervisores situados no nível mais baixo da hierarquia de funcionários do hospital - e os pacientes. Tal proximidade era explicada pela falta de identificação dos primeiros com o grupo de seus superiores, que se constituía de indivíduos com formação profissional e nível social mais elevado. Todavia, tal aproximação abarcava um sentido ambíguo, tendo em vista o ponto de vista funcional subjacente à autoridade formal, como sugere o seguinte trecho:

A proximidade que os atendentes têm, do ponto de vista de sua origem sociocultural e econômica, com os internos faz com que sejam eles os que [sic] mais adequadamente realizam a leitura das necessidades e das aflições destes. Os atendentes, se, por um lado, encontram-se muito próximos dos internos, por outro, necessitam (e para isso sempre são alertados pelos enfermeiros) diferenciar-se, para que não se identifiquem com a loucura, nem com os demais aspectos constituintes da situação precária e desamparada de que os internos são porta-vozes eloqüentes (Teixeira, 1993, p. 84-5.)

Por fim, Goffman considera o problema da mortificação do eu como resultado da orientação racional-instrumental que predomina nas instituições totais. Ela é configurada pela ênfase no controle e na eficiência de recursos proporcionada pelo aparato burocráti$\mathrm{co}$, que ocorre independentemente do sentido moral que possa vir a ocorrer na relação dos dirigentes com os internos.

A caracterização das organizações totais serve para que se possa verificar melhor a contradição que envolve as instituições psiquiátricas. A diferença entre o objetivo oficial - a cura da doença mental - e o caráter funcional assumido pela instituição manicomial - o isolamento e o controle da loucura - denota uma ambigüidade que pode ser medida pelo sentido utilitarista assumido pelas instituições modernas. Esse sentido expressa-se na questão dos manicômios pela efetividade que teve a integração entre o cientificismo da psiquiatria e o uso instrumental das políticas públicas da medicina social (Machado et al., 1978; Foucault, 1997). Seguindo a crítica à razão instrumental expressa na teoria social crítica de Habermas (1987), por exemplo, o tipo manicomial configura-se como uma organização eminentemente orientada no sentido de uma ação social estratégica, em que a relação médico-paciente constitui-se de modo monológico, em razão exclusivamente do interesse objetivo do primeiro em determinar as atitudes do segundo. A falta de reciprocidade nas interações formais - dada pelo não reconhecimento da categoria inferior como sujeitos competentes e pertencentes à mesma condição - transparece no sentido diverso atribuído aos discursos das duas classes elementares nas orga- 
nizações manicomiais (pacientes/equipe dirigente), como demonstra a diferenciação que Birman et al. fazem entre os discursos do paciente e da equipe técnica:

Com isso se demarca o sentido de cada um destes discursos: o dos pacientes é um discurso de expressão, isto é, seu valor (quando conferido pela instituição) é o de manifestar, seja como sintoma, seja como catarse, a patologia do paciente; seu circuito é desigual, pois não há reciprocidade: uma vez dito não lhe corresponde resposta, permanecendo isolado, no máximo servindo como material de outro discurso, o técnico. Este, por sua vez, consiste numa permanente apropriação da fala do paciente, passando-se numa esfera a que este não tem acesso e se desdobrando segundo códigos (de saber) aos quais o paciente está alheio, exceto em seus efeitos terapêuticos e de controle (Birman et al., 1988, p. 82).

Assim, a comunicação, quando existe, passa a ser determinada de forma manipuladora. Em nome do interesse instrumental, são utilizados todos os recursos de distorção comunicativa para a obtenção do consentimento do paciente (assim como pode ocorrer no sentido de combater as insurgências morais contra a estrutura manicomial). Nesse sentido, as principais distorções de comunicação ocorrem no uso estratégico da informação documentada (disponível apenas para o corpo dirigente) e pelo emprego de uma linguagem técnica que dificulta tanto a inteligibilidade na comunicação quanto o reconhecimento da autenticidade no discurso da equipe dirigente (dada a impessoalidade subjacente ao uso de uma terminologia técnica). Dessa forma, o uso instrumentalmente orientado da linguagem na forma de discurso técnico, além de representar um efetivo mecanismo de dominação (Birman et al., 1988), corrobora a idéia de que a própria estrutura burocrática de controle constitui um importante fator estrutural de distorção comunicativa (Felts, 1992; Forester, 1994).

Esse interesse manipulador pode ser observado na postura assumida pelos funcionários do manicômio, mesmo quando estão em jogo elementos estruturais de relações interpessoais eminentemente de natureza recíproca. Machado et al. (1978, p. 444), por exemplo, descrevem a postura do psiquiatra em relação à confiança: "Quando o médico adquire confiança do louco, ele vê nisso uma vitória importante para a conquista da obediência: o alienado passa a ouvir o médico, a abandonar-se em suas mãos, diminuindo ou anulando sua reação, despojando-se do seu próprio poder de oposição".

A falta de reciprocidade no processo comunicativo entre os membros da organização manicomial também pode ser auferida de dois fatores fundamentais da organização burocrática de controle: 
a) a delimitação formal da jurisdição de ação, que é derivada da autoridade formal; eb) a predominância da competência perita como fonte de legitimidade da ação, dada a necessidade de especialização e profissionalização dos ofícios. Esses fatores são cruciais; para determinar a unilateralidade das interações no âmbito de toda a organização (tendo em vista que são determinantes não somente nas relações entre supervisores e pacientes, mas também entre os membros da equipe dirigente). E também são importantes premissas do processo decisório das organizações manicomiais. A relevância que tem o conhecimento especializado em organizações médico-hospitalares contribui para que se construa uma cadeia de poder dos peritos (Mintzberg, 1995) que faz com que as decisões sejam tomadas exclusivamente em função do cargo funcional ou do sistema de regras formais. Todavia, é comum a manipulação de tais aparatos formais para a tomada de decisões em benefício próprio. Neste caso, a argumentação se processa em razão do conhecimento técnico possuído pelo especialista, que atua de maneira a confundir seus interlocutores e fazer valer seu interesse.

Basicamente, a contraposição ao modelo manicomial ocorre de três formas: o movimento antimanicomial, a antipsiquiatria e a reforma psiquiátrica. Embora se considere que as três integram um mesmo movimento de ruptura com a ciência e as técnicas psiquiátricas modernas, didaticamente podem ser apresentadas em separado. Vejamos a seguir suas principais características, assim como o reflexo que esses movimentos tiveram sobre a formulação de um novo modelo organizacional, centrado em bases distintas da lógica burocrática.

\section{O movimento antimanicomial, a antipsiquiatria e a reforma psiquiátrica}

A luta antimanicomial corresponde a um movimento ativista em prol dos direitos humanos transgredidos nos manicômios. Tem por objetivo principal a denúncia do tratamento desumano dado aos pacientes. Isso se deu a partir de um engajamento político de entidades da sociedade civil que denunciavam os horrores dos manicômios e exigiam das autoridades medidas contra tais instituições. Também alguns profissionais da área de saúde mental se engajaram na causa antimanicomial, pois estavam preocupados com a ambigüidade subjacente ao modelo asilar de tratamento, considerada especialmente pela discrepância entre o compromisso médico de curar e a obsessão pela disciplina e controle dos internos. Muitos estudos empíricos em instituições psiquiátricas brasileiras foram efetuados com este propósito de denúncia, como, por exemplo, os de Birman et al. (1988), Cunha (1986) e Teixeira (1993). 
Para o movimento da luta antimanicomial, importante foi o trabalho do psiquiatra italiano Franco Basaglia - ativista, pesquisador e intelectual que muito contribuiu para a concretização de uma nova perspectiva com relação ao doente mental e às profissões ligadas ao tratamento psiquiátrico. Suas idéias tiveram forte influência em vários países e deram ensejo ao surgimento de diversos esforços reformistas (Amarante, 1996). Recentemente, no Brasil, a mobilização dos ativistas do movimento antimanicomial culminou na formulação de uma lei federal que dispõe sobre a reformulação do modelo tradicional de tratamento psiquiátrico, visando a regulamentar as instituições psiquiátricas para que percam seu caráter 'manicomial' (Lei 10.216, de 6 de abril de 2001).

A antipsiquiatria corresponde a um movimento no qual se questiona a validade da psiquiatria como metodologia científica de tratamento da doença mental. Seus proponentes buscam questionar epistemologicamente a disciplina psiquiátrica como forma de saber centrada numa lógica causal e analítico-empírica, e, por isso, não competente para tratar da questão loucura, eminentemente subjetiva e não circunscrita ao âmbito objetivo da realidade. Cooper (1967), por exemplo, empreende sua crítica à psiquiatria considerando os limites ontológicos da perspectiva empírico-analítica dessa disciplina, especialmente no que tange à apreensão de patologias manifestadas intersubjetivamente, tal como a esquizofrenia. Considera este autor:

A racionalidade implícita de semelhantes teorias causalistas, à qual denominamos racionalidade analítica, exclui, por definição, qualquer compreensão de relações de interioridade entre pessoas (às vezes chamadas de intersubjetividade), e, no entanto, são tais relações que medeiam a série de atos que chamamos de "comportamento esquizofrênico", ou seja, a maneira pela qual a pessoa rotulada de esquizofrênico se objetiva no mundo. Se quisermos compreender esta mediação, se quisermos descobrir a inteligibilidade do comportamento esquizofrênico, ou de qualquer outra espécie de comportamento, necessitamos não apenas de certa técnica descritiva especial, porém de um tipo de racionalidade radicalmente distinto da racionalidade analítica da ciência natural (id. ibid., p. 23).

Ao comentar um texto de Laing (um dos mais proeminentes autores da antipsiquiatria), Bosseur (1976) ressalta o teor epistemológico da crítica deste autor ao modelo de ciências naturais, especialmente quanto à postura objetivante do psiquiatra. A antipsiquiatria busca, com novas perspectivas acadêmicas (como por exemplo a fenomenologia e o existencialismo), o fundamento teórico para criticar o conhecimento psiquiátrico, identificado como mais uma forma de discurso de dominação. Assim, segundo 
Foucault (1992, p. 113-28), a antipsiquiatria tem por fundamento o questionamento do saber/poder do médico em proferir a verdade sobre a loucura.

A antipsiquiatria questiona o próprio papel do psiquiatra, considerando constrangedora a sua postura na relação com o paciente, e, portanto, insuficiente no processo de cura da enfermidade psíquica. A crítica à psiquiatria, então, também reside na unilateralidade assumida pelo psiquiatra em uma relação comunicativa distorcida e não natural (Duarte Jr., 1986).

A partir das críticas ao modelo psiquiátrico tradicional surge então a idéia de reforma psiquiátrica. Amarante (1996) indica três vertentes elementares desse movimento. Numa perspectiva mais radical, tem-se como proposta reformadora a extinção da instituição hospitalar (desospitalização), entendida como a principal tecnologia causadora da degradação do doente mental. Todavia, também se considera a grande limitação dessa vertente do movimento reformista, entendida como uma solução paliativa, denotando novos problemas, como indica o seguinte trecho:

Embora nascida como crítica à aplicação do modelo psiquiátrico, a desinstitucionalização, nesta versão, propicia uma ampliação do território psiquiátrico, isto é, alarga o conceito de doença para o de desvio, mal-estar social, desajustamento, anormalidade. Com isso, produz-se um efeito rebote, pois criam-se inúmeros novos serviços, especialidades e técnicas, que, em uma palavra, aumentam o número de pessoas assistidas e as possibilidades de intervenção técnica, sem que os resultados terapêuticos sejam correspondentes (id. ibid., p. 17).

A insustentabilidade da perspectiva da desospitalização também reside no fato de que o modelo manicomial não se resume à organização física da instituição hospitalar em si, mas a um conjunto de normas, procedimentos e regras que compõem tal lógica institucional (Giovanella et al., 1994).

Outras duas perspectivas de reforma apresentadas por Amarante são o desassistencialismo e a desconstrução da instituição psiquiátrica. O primeiro tem como contrapartida a idéia de desospitalização, pois considera que "a desinstitucionalização significaria abandonar os doentes à própria sorte, seja pela premissa crítica, correta, de que seu objetivo pode ser o de reduzir ou erradicar a responsabilidade do Estado para com estas pessoas e familiares, seja por uma compreensão pouco correta do conteúdo teórico que está em jogo" (Amarante, 1996, p. 18-9). Entretanto, essa perspectiva tem sido desabonada, por estar comumente vinculada aos segmentos que detêm interesses econômicos na manutenção do atendimento médico-hospitalar.

Assim, surge a terceira perspectiva reformista, a desconstrução da instituição, "caracterizada pela predominância da crítica 
epistemológica ao saber médico constituinte da psiquiatria" (id. ibid., p. 20). Nessa abordagem surge uma preocupação com medidas que estejam vinculadas a uma mudança de perspectiva quanto ao saber médico e, por conseqüência, ao tratamento da doença mental, além da própria concepção de loucura. Desse modo, Amarante diz que

os passos iniciais da desinstitucionalização consistem, pois, no descontruir o paradigma problema-solução, no envolver e mobilizar nesse processo os atores sociais envolvidos, inclusive os internos - já não mais sob o critério de "desalienação" -, o que permite descobrir que esse não é um problema puramente tecnocientífico, mas também normativo, social e ético (id. ibid., p. 76).

O questionamento da estrutura formal e burocratizante do modelo organizacional manicomial e a constatação do seu caráter degradante e ideológico representariam o resultado de tal "atitude epistemológica" (Giovanella et al., 1994, p. 138) pregada pela vertente desconstrucionista da reforma psiquiátrica. A transformação da lógica de interação humana no âmbito dos hospitais passaria necessariamente por um processo de democratização do poder, visto como uma conseqüência do sentido humanitário envolvido na causa reformista, além do próprio reconhecimento do paciente como sujeito e igual. Na verdade, a ruptura com o poder subjacente à autoridade médica, que se pretende na psiquiatria objetivada pelo movimento reformista, perpassa o princípio de reconhecimento mútuo. Como indica Cassorla (1995), é o reconhecimento da humanidade do paciente e do médico que tem direcionado uma nova postura do médico.

Várias propostas tentam concretizar essa mudança da perspectiva unilateral subjacente à instituição médico-hospitalar tradicional para uma forma mais igualitária entre o corpo dirigente e os pacientes. Uma delas é a inserção de um sentido de 'comunidade' no âmbito da organização psiquiátrica. Apesar de identificarem sérios problemas na sua forma conceitual original (fundamentada pela psiquiatria britânica, um grupo vinculado a muitos dos pressupostos do paradigma científico dominante), Basaglia et al. (1994) percebem na idéia de 'comunidade terapêutica' um forte potencial emancipatório dos problemas gerados pelo caráter ideológico assumido na prática psiquiátrica tradicional. Os autores consideram que o conceito de comunidade terapêutica pressupõe uma contraposição à relação tradicional médico-paciente, tendo em vista ser esta forma "um conjunto orgânico não hierarquizado de médicos, pacientes e pessoal auxiliar" (id. ibid., p. 13). Todavia, ressaltam que, dados os conflitos e ambigüidades que marcam o processo de democratização, pode ser que surja uma ideologia 
2 Ou seja, as abordagens que não se valem dos pressupostos positivistas (Burrell et al., 1979). Entre elas, a fenomenologia de Schutz, o

interacionismo simbólico de Mead, a sociologia interpretativa de Weber e mesmo a teoria crítica de Habermas. comunitária a representar uma nova forma de controle e dominação grupal. Para impedir tal anomalia, faz-se necessário o favorecimento da autocrítica e da autocontestação, que devem permear tanto o processo reflexivo individual quanto o coletivo.

Vemos claramente, na concepção de comunidade terapêutica, o mesmo fundamento epistemológico que sustenta as teorias sociológicas críticas - como por exemplo a teoria da ação comunicativa de Habermas (1987): de que a ação genuinamente democrática subsiste em um sistema interativo dialógico, não manipulador e aberto à discussão. Na verdade, a possibilidade de uma discussão e de uma reflexão como via de construção de uma ética social perpassa a própria concepção de desinstitucionalização (Amarante, 1996).

Sob o ponto de vista estrutural, as medidas reformistas podem ser consideradas como fortes indicações de uma significativa mudança no instituto organizacional psiquiátrico, especificamente no que tange a uma provável ruptura com a lógica racional-instrumental do modelo burocrático de organização e controle. Tendo por referência uma crítica epistemológica à relação monocrática entre o corpo dirigente e os pacientes, as propostas reformistas visam a efetivar mecanismos de coordenação da atividade organizacional que se pretendem mais amparados em um sentido dialógico. Aí pressupõe-se que ambos os atores sociais - pacientes e terapeutas - sejam considerados sujeitos ativos e competentes de uma relação social.

\section{Considerações finais}

A partir das abordagens sociológicas não funcionalistas, ${ }^{2}$ que cada vez mais vêm se desenvolvendo no campo acadêmico, muitas críticas ao formato psiquiátrico de controle organizacional têm sido feitas. Tido como reflexo de um processo maior de sistematização da vida social, em que o interesse econômico e o cientificismo surgem como valores centrais para o estabelecimento das instituições modernas (Santos, 1988), a burocracia, como lógica organizacional, tem configurado uma das mais patentes contradições do projeto iluminista, sobretudo pelo caráter desumanizante da lógica burocrática de controle social (Weber, 1974). O instituto psiquiátrico moderno, por ter sido engendrado a partir dos mesmos pressupostos que deram ensejo ao processo de secularização e cientificismo da modernidade, não deixa de abarcar o mesmo componente ideológico, justamente no que tange à adoção do alienismo como principal técnica psiquiátrica moderna. Mesmo a profissionalização da prática psiquiátrica, entendida pelo pensamento acadêmico da época como um refinamento positivo ao tratamento da loucura, servia antes como forma de controle da loucura e de tantos outros desvios sociais. 
${ }^{3}$ Ressalva deve ser feita quanto ao caráter positivo das mudanças epistemológicas obtidas pela antipsiquiatra e pela reforma psiquiátrica. Seria ingênuo crer que tais movimentos também não abarcam uma lógica de dominação - às vezes, mais profunda que a dominação burocrática, por ser revestida pela idéia humanitária. Todavia, é importante destacar que as transformações sociais que deram ensejo a tais movimentos reformistas já são em si indícios de uma mudança paradigmática positiva. Quanto a essa questão, agradecemos a contribuição dos avaliadores do presente artigo.
É assim que, a partir do desenvolvimento histórico do instituto psiquiátrico, vemos o processo de reforma psiquiátrica da instituição hospitalar como um caso expressivo de tentativa de ruptura com o modelo burocrático de administração e coordenação da ação. A orientação para a eficiência subjacente à lógica burocrática entendida como uma questão historicamente constituída e que se apresenta para o tratamento da doença mental como uma forte contradição - é substituída, na reforma psiquiátrica, por uma orientação mais humanista, na qual aspectos éticos e morais também são considerados na elaboração e execução das medidas terapêuticas. Essa nova orientação transparece especialmente no sentido de reciprocidade pressuposta na relação entre equipe dirigente e pacientes (sobretudo por meio da idéia de comunidade terapêutica), antes vista como uma relação monológica. Nesse sentido, a contraposição ao esquema burocrático é notória quando se busca romper com a autoridade formalmente instituída do médico, seja pela negação do saber do psiquiatra, seja pela negação do mandato social de custódia do paciente (Basaglia et al., 1994). Na reforma psiquiátrica também se preconiza a inserção do doente mental nos espaços sociais de que antes ele era privado. Tal fato indica existir um reconhecimento desse ator como sujeito ativo e competente, ao contrário do que ocorre na lógica burocrática, em que o paciente é tido como um objeto a ser manipulado pelos especialistas.

Além disso, as propostas da reforma psiquiátrica - apesar de ainda não configurarem uma mudança consolidada no modelo organizacional da instituição psiquiátrica - representam aspectos significativos a delimitar um novo horizonte para uma determinada sociedade. Esta última vem sendo marcada pela desumanização do homem, com o advento de uma lógica de controle social impessoal e centrada exclusivamente no resultado técnico e econômico (Weber, 1974). Tal promessa emancipatória se consolida especialmente pelo fato de que tanto o movimento antimanicomial quanto o da reforma psiquiátrica representam epistemologias alternativas à lógica positivista de pensamento e organização social da modernidade $^{3}$. E também por abarcarem o germe de um novo entendimento da doença mental que vem se desenvolvendo de modo gradual. 


\section{REFERÊNCIAS BIBLIOGRÁFICAS}

Amarante, Paulo 1996

Argyris, Chris 1975

Basaglia, Franco et al. 1994

Birman, Joel et al. 1988

Bosseur, Chantal 1976

Burrell, Gibson et al. 1979

Cassorla, Roosevelt 1995

Cooper, David 1967

Cunha, Maria

Clementina P. 1986

Duarte Júnior,

João Francisco 1986

Felts, Arthur fev. 1992.

Forester, John jan.-jun. 1994

Foucault, Michel 1997

Foucault, Michel 1992

Foucault, Michel 1987

Giovanella, Lígia et al. 1994

Goffman, Erving 1996

Habermas, Jürgen 1987

Machado, Roberto et al. 1978

Mintzberg, Henry 1995
O homem e a serpente: outras histórias para a loucura e a psiquiatria. Rio de Janeiro, Fiocruz.

A integração indivíduo-organização.

São Paulo, Atlas.

Considerações sobre uma experiência comunitária.

In Amarante, Paulo (org.). Psiquiatria social e reforma psiquiátrica.

Rio de Janeiro, Fiocruz, p. 11-40.

Os descaminhos da subjetividade.

Niterói, Ed. da Universidade Federal Fluminense.

Introdução à antipsiquiatria.

Rio de Janeiro, Zahar.

Sociological paradigms and organisational analysis: elements of the sociology of corporate life. Londres, Heinemann Educational Books.

Prefácio. In Botega, Neuri José Botega (org.).

Serviços de saúde mental no hospital geral. Campinas, Papirus, p. 7-14.

Psiquiatria e antipsiquiatria.

São Paulo, Perspectiva.

O espelho do mundo: Juquery, a história de um asilo.

Rio de Janeiro, Paz e Terra.

A política da loucura: a antipsiquiatria.

$2^{\mathrm{a}}$ ed. Campinas, Papirus.

Organizational communicatio.

Administration $\mathcal{E}$ Society, v. 23, n. 4, p. 495-517.

Teoria crítica e análise organizacional.

Plural, v. 1, p. 131-48.

História da loucura.

5a ed. São Paulo, Perspectiva.

Microfísica do poder.

$10^{\mathrm{a}}$ ed. Rio de Janeiro, Graal.

Vigiar e punir: o nascimento da prisão.

$5^{\underline{a}}$ ed. Petrópolis, Vozes.

O enfoque estratégico do planejamento em saúde e saúde mental.

In Amarante, Paulo (org.). Psiquiatria social e reforma psiquiátrica.

Rio de Janeiro, Fiocruz, p. 113-47.

Manicômios, prisões e conventos.

5ª ed. São Paulo, Perspectiva.

Teoría de la acción comunicativa.

2 v. Madri, Taurus.

Danação da norma: a medicina social e constituição da psiquiatria no Brasil. Rio de Janeiro, Graal.

Criando organizações eficazes: estruturas em cinco configurações.

São Paulo, Atlas. 
Santos, Boaventura

Souza maio-ago. 1988

Teixeira, Mário 1993

Weber, Max 1991

Weber, Max 1974
Um discurso sobre as ciências na transição para uma ciência pós-moderna. Estudos Avançados, v. 2, n. 2, p. 46-71.

Hospício e poder.

Brasília, Editora do Senado Federal.

Economia e sociedade: fundamentos da sociologia compreensiva. v. 1. Brasília, Editora UnB.

Ensaios de sociologia.

Rio de Janeiro, Zahar.

Recebido para publicação em março de 2003.

Aprovado para publicação em abril de 2004. 